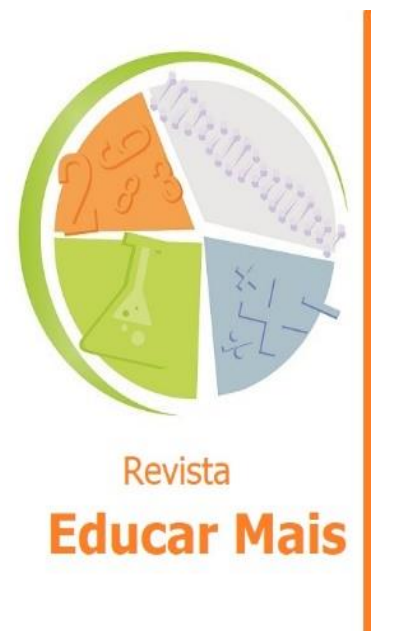

\section{Ginástica laboral como intervenção e melhoria na qualidade de vida docente}

\author{
Labor gymnastics as intervention and improvement in the quality of \\ teaching life
}

\section{La gimnasia laboral como intervención y mejora em la calidad de vida docente}

Marinalva Sampaio Guimarães ${ }^{1}$; Maria Luiza Mendonça Azevedo²; Thiago Rocha Amaro3; Virgínia Mara Próspero Cunha $^{4}$; Maria Teresa de Moura Ribeiro ${ }^{5}$; Marilza Terezinha Soares de Souza ${ }^{6}$

\title{
RESUMO
}

O trabalho docente pode provocar desgaste físico e emocional resultando no aumento do nível de estresse, aparecimento de doenças como depressão e lesões por esforços repetitivos, ocasionando licenças no emprego. Nesse contexto, objetivou-se com o presente relato de experiência promover conscientização sobre a importância da prática de atividade física regular incentivando a qualidade de vida docente. Para tanto, utilizouse a prática de Ginástica Laboral como intervenção com um grupo de 10 professores de uma escola privada do Ensino Fundamental, localizada em um município do interior paulista. Esse tipo de exercício é realizado no local de trabalho com a finalidade de contribuir na prevenção de doenças e favorecer o relacionamento interpessoal. Autores como Ferrão (2012), Zankoski (2013) e Silva, Baia, Romanholo, Soares (2015) embasaram teoricamente o estudo. Conclui-se que os efeitos da Ginástica Laboral contribuíram para promover a motivação pela prática de atividades físicas, além de proporcionar bem-estar. Sugerem-se pesquisas futuras que evidenciam a possibilidade de realizar exercícios físicos em casa, utilizando como recurso canais do YouTube.

Palavras-chave: Ginástica Laboral; Qualidade de Vida Docente.

\begin{abstract}
School job could provoke physical and emotional distress, which result in a increase of stress, new infirmities like depression and repetitive strain injuries, which cause work leave. In this context, the objective of this experience report was to promote awareness of the importance of regular physical activity, encouraging the quality of teaching. For that, we used the practice of Labor Gymnastics with a group of 10 teachers from a private elementary school, located in a country city of São Paulo State. This type of exercise is performed in the workplace in order to contribute to disease prevention and to favor interpersonal relationships. Authors such as Ferrão (2012), Zankoski (2013) and Silva, Baia, Romanholo, Soares (2015) theoretically supported the study. It is concluded that the effects of Labor Gymnastics contributed to promote motivation for the practice
\end{abstract}

\footnotetext{
${ }^{1}$ Mestranda em Educação na Universidade de Taubaté, SP. E-mail: marinalvasampaiogui@gmail.com

2 Mestranda em Educação na Universidade de Taubaté, SP. E-mail: malu_mendonca@hotmail.com

3 Mestrando em Educação na Universidade de Taubaté, SP. E-mail: thiagoamaro451@yahoo.com.br

${ }^{4}$ Doutorado e Mestrado em Educação. Professora Assistente III da Universidade de Taubaté, SP. E-mail: vimaracunha@terra.com.br

${ }^{5}$ Doutorado e Mestrado em Educação. Professor Assistente Doutor da Universidade de Taubaté, SP. E-mail: mterib@hotmail.com

${ }^{6}$ Pós-Doutorado em Psicologia Clínica, Doutorado em Psicologia e Mestrado em Saúde Mental. Professora aposentada do Departamento de Psicologia da Universidade de Taubaté, SP. E-mail: de_souzamarilza@hotmail.com
} 
of physical activities, in addition to providing well-being. Future research is suggested that show the possibility of performing physical exercises at home, using YouTube channels as a resource.

Keywords: Labor Gymnastics; Quality of Life.

\section{RESUMEN}

El trabajo docente puede causar agotamiento físico y emocional, lo que resulta en un aumento del nivel de estrés, aparición de enfermedades como depresión y lesiones por esfuerzo repetitivo, lo que implica en licencia de trabajo. En este contexto, el objetivo de este relato de experiencia fue promover la conciencia de la importancia de la actividad física regular, fomentando la calidad de vida de los profesores. Para eso, utilizamos la práctica de Gimnasia Laboral como intervención con un grupo de 10 profesores de una escuela primaria privada, ubicada en una ciudad de São Paulo. Este tipo de ejercicio se realiza en el lugar de trabajo con el propósito de contribuir a la prevención de enfermedades y favorecer las relaciones interpersonales. Ferrão (2012), Zankoski (2013) y Silva, Baia, Romanholo, Soares (2015) apoyaron teóricamente el estudio. Se concluye que los efectos de la Gimnasia Laboral contribuyeron a promover la motivación para la práctica de actividades físicas, además de brindar bienestar. Se sugieren futuras investigaciones que muestren la posibilidad de realizar ejercicios físicos em casa, utilizando los canales de YouTube como recurso.

Palabras clave: Gimnasia Laboral; Calidad de Vida Docente.

\section{INTRODUÇÃO}

De acordo com Silva, Baia, Romanholo, Soares (2015), a ausência da prática de atividade física é um fator que pode contribuir para o desenvolvimento de doenças crônicas não transmissíveis. Os autores afirmam também que em se tratando do professor, a própria dinâmica de trabalho docente favorece o sedentarismo por não exigir esforço físico.

Relacionando ao âmbito educacional, o cuidado com o bem-estar do ser humano nos aspectos físico e emocional é uma preocupação existente na Base Nacional Comum Curricular, documento que norteia as aprendizagens essenciais que os alunos devem desenvolver, desde a Educação Infantil até o Ensino Médio e perpetuar ao longo da vida. "Conhecer-se, apreciar-se e cuidar da sua saúde física e emocional, compreendendo-se na diversidade humana e reconhecendo suas emoções e as dos outros, com autocrítica e capacidade para lidar com elas." (BRASIL, 2018, p.10). Sendo assim, atentar-se para a qualidade de vida é uma necessidade e competência a ser adquirida ao longo do desenvolvimento humano e não somente na idade adulta.

Andrade e Veiga (2012) salientam que a maioria das pessoas vive em um contexto de trabalho competitivo e tecnológico no qual a exigência por melhores resultados é tão grande quanto o nível de estresse do funcionário.

A falta de atividade física é uma realidade de grande parte da população e, apesar de existir um consenso sobre a importância de praticar exercícios para o benefício da saúde em todos os sentidos, o excesso de trabalho faz com que se exercitar deixe de ser prioridade para muitas pessoas.

Considerando o modelo de sociedade atual, imediatista, tecnológico e competitivo, o trabalhador em sua função necessita superar metas, gerando cada vez mais lucro para as empresas, ou seja, ter espírito competitivo é elemento fundamental nesse processo. Por essa razão, para as instituições que anseiam superar a concorrência nos atuais mercados globalizados é crescente a preocupação com a qualidade de vida dos funcionários. Nesse viés, algumas empresas adotam um programa de qualidade 
de vida do trabalhador, que geralmente oferece ginástica laboral (GL) visando à prevenção de doenças, promoção da saúde e em consequência, a produtividade.

Os programas de qualidade de vida no trabalho (PQVT) subsidiam atividades que favorecem a prevenção e a promoção da saúde, atendendo as necessidades mais amplas do trabalhador, sendo assim, buscam conciliar o interesse dos empregados e da organização (ANDRADE; VEIGA, 2012, p. 306).

A Ginástica Laboral consiste na realização de uma série de exercícios físicos no local de trabalho, com a finalidade de atender as necessidades do funcionário. Pode contribuir na prevenção de doenças e promover qualidade de vida, melhorar a flexibilidade e postura corporal, além da interação entre os participantes, favorecendo o relacionamento interpessoal. Brito e Martins (2012) ressaltam que

Investir na saúde dos colaboradores não é perder dinheiro, mas gerar aumento da produtividade, principalmente pelo fato de o trabalhador se encontrar mais saudável, além de ter a chance de reduzir índices de absenteísmo e de presenteísmo, diminuir gastos com despesas médicas e reduzir o tempo perdido com treinamentos de substitutos (BRITO; MARTINS, 2012, p. 451).

A Ginástica Laboral é uma das formas que instituições encontram para proporcionar aos seus funcionários qualidade de vida e incentivá-los abandonar o sedentarismo, tendo como objetivo combater o estresse para que assim o profissional melhore o rendimento no trabalho e sua relação nos grupos sociais. Zamban e Costa (2013) afirmam que:

A Ginástica Laboral é a prática de exercícios, realizada coletivamente, durante a jornada de trabalho, prescrita de acordo com a função exercida pelo trabalhador, tendo como finalidade a prevenção de doenças ocupacionais, promovendo o bemestar individual, por intermédio da consciência corporal: conhecer, respeitar, amar e estimular o seu próprio corpo. Ainda através da GL o homem reflete sobre a importância do seu corpo no seu trabalho (ZAMBAN; COSTA, 2013, p.3).

Ferrão (2012) cita que a ginástica laboral traz como benefícios a diminuição nos números de falhas, visto que os profissionais estão mais atentos e tem motivação para o exercício do trabalho, reduz o gasto com despesas médicas, diminuição no número de acidentes, melhora na concentração no ambiente de trabalho e aumento na produtividade.

A Ginástica Laboral é uma prática que tem por finalidade a promoção de saúde no ambiente de trabalho, prevenindo o surgimento ou agravo das doenças ocupacionais proporcionando o bem-estar individual do trabalhador. Nesse contexto, ativa principalmente os músculos que são mais utilizados na realização de sua atividade profissional, proporcionando qualidade de vida. A pessoa ao ser orientada na realização dos exercícios melhora sua postura, sua percepção quantos aos benefícios dessa prática aumenta e ocorre a diminuição dos processos de dor. Os profissionais habilitados para ministrar essa modalidade de exercício atuam utilizando princípios de ergonomia que consiste em um conjunto de medidas de prevenção para a diminuição de problemas em seu ambiente ocupacional trazendo saúde e segurança aos praticantes. (BRITO; MARTINS, 2012).

Segundo Lima (2004) a ginástica laboral promove ações positivas para o funcionário, sendo eficaz para combater a fadiga, por exemplo, como atividade compensatória, pois é capaz de minimizar a insatisfação dos trabalhadores com a rotina de trabalho, garantindo produtividade em suas funções.

A Ginástica Laboral pode auxiliar na melhora quanto às posturas inadequadas e diminuir a sobrecarga dos movimentos repetitivos durante a jornada de trabalho, sendo então possível com essa prática, preparar o corpo para o trabalho físico. Contribui na prevenção das doenças osteomuscular 
relacionada ao trabalho e pôr fim a diminuição do stress. Mó, Vieira e Santos (2010) reforçam que "As expectativas destes métodos apontam também para a diminuição do número de acidentes de trabalho, a prevenção da fadiga muscular e uma maior integração no ambiente de trabalho".

Entretanto, os programas de qualidade de vida não são realidade em todas as esferas empregatícias. No campo educacional, por exemplo, as escolas em sua maioria não dispõem desse serviço. Professores possuem dupla jornada de trabalho e tempo escasso para se exercitar. Silva, Baia, Romanholo, Soares (2015) em suas pesquisas constataram que os professores acreditam que a prática regular de atividades físicas traz benefícios a saúde, porém o estilo de vida sedentário não condiz com a afirmativa.

No tocante ao estilo de vida dos trabalhadores, sobretudo dos professores, o relato de experiência tem como objetivo geral compartilhar o caminho percorrido pela ação na escola no intuito de promover a conscientização sobre a importância da prática de atividade física regular aliviando as tensões e promovendo a qualidade de vida docente. De acordo com o objetivo geral, tenciona-se com os objetivos específicos motivar os professores para a prática de atividades físicas, despertar o interesse por hábitos de vida saudável, favorecer as relações interpessoais e disponibilizar material informativo na forma de infográfico.

O projeto "Ginástica Laboral como intervenção e melhoria na qualidade de vida docente" justifica-se pela necessidade de apresentar aos professores uma ferramenta capaz de favorecer em diferentes aspectos a qualidade de vida dos participantes, uma vez que grande parte deles possui jornadas de trabalhos longas e se dividem em outras funções, a atividade física não é prioridade e o sedentarismo ocasiona prejuízos à saúde da pessoa. Tendo exposto o problema, os objetivos e a justificativa do estudo pelos alunos pesquisadores do curso de Mestrado Profissional em Educação da Universidade de Taubaté e após discussões em sala de aula na disciplina Escola, Currículo e Diversidade, a ação interventiva foi planejada para sua aplicabilidade em uma escola com professores do Ensino Fundamental.

\section{METODOLOGIA}

Trata-se de um relato de experiência no qual é possível compartilhar as experiências vividas em uma ação desenvolvida em uma escola.

A partir do planejamento das tarefas a serem alcançadas, iniciaram-se as atividades para a concretização dos objetivos. No primeiro momento foi realizada uma reunião com a equipe gestora e professores de uma escola privada de Ensino Fundamental I, localizada em um município do Vale do Paraíba paulista, para explanação da proposta de intervenção da Ginástica Laboral com os professores da unidade escolar. Após aprovação de todos os envolvidos, os 10 docentes que fazem parte da instituição foram convidados em uma reunião pedagógica, a assistir uma palestra ministrada por um professor de Educação Física com a temática "Qualidade de Vida e Hábitos de Saúde". Ao final os docentes iniciaram a realização da Ginástica Laboral e foram informados que a partir daquele momento, duas vezes por semana, o professor se reuniria com o grupo para a prática de exercícios físicos com duração média de 15 minutos, em um período de 45 dias. Durante o desenvolvimento das propostas, os participantes da ação interventiva acolheram as orientações do profissional habilitado e receberam um material infográfico com informações relevantes sobre a prática regular de exercícios físicos. 
FIGURA 1 - Material Infográfico
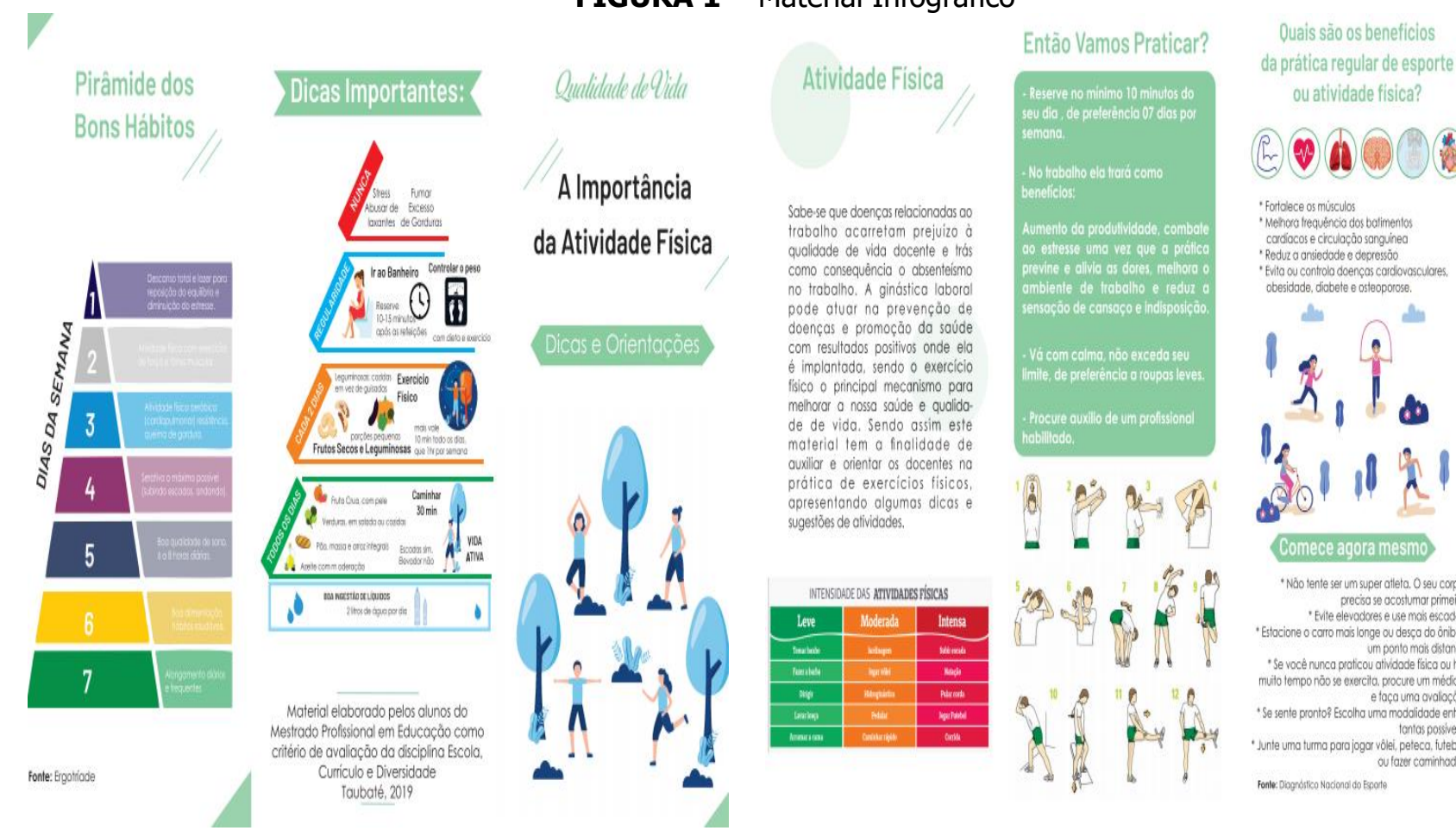

Fonte: Desenvolvido pelos pesquisadores, 2021.

\subsection{A IMPORTÂNCIA DA ATIVIDADE FÍSICA E A QUALIDADE DE VIDA DOCENTE}

O ofício de docente pode contribuir para o desgaste físico e emocional desses profissionais que realizam suas atividades escolares. Isto traz como consequência o aumento do nível de stress e aparecimento de doenças relacionadas à sua ocupação como depressão, ansiedade, aparecimento de lesões por esforços repetitivos (LER), o que acarreta afastamentos e licenças por longos períodos (BAZANI; GOES; RIBAS, 2001).

Os professores possuem uma carga horária de trabalho exaustiva, o que acaba prejudicando o bemestar. A falta de tempo para cuidar da saúde em detrimento da execução de tarefas que proporcionam prazer ocasiona às pessoas sedentárias, além do fator de risco de diversas doenças, a tensão, estresse e desmotivação no trabalho.

A profissão docente, o próprio ambiente de trabalho, as diversas funções exigidas pelo cargo, cobranças por resultados e prazos para realização das atividades são questões capazes de trazer ao professor problemas físicos e emocionais com destaque para os problemas osteomusculares, depressão, ansiedade entre outros. As situações de saúde que ocorrem dentro do ambiente de trabalho têm sido vista como fenômeno social, ou seja, necessitando de uma equipe multidisciplinar além do acompanhamento médico, o suporte de psicólogos, educadores físicos entre outros profissionais que conjuntamente atuam para a melhoria da condição de saúde docente (DOMINIENSE; MAN, 2016).

Nos últimos anos é possível verificar que os profissionais permanecem a maior parte do seu dia dentro do ambiente de trabalho, em especial alguns docentes que atuam em jornadas longas dificultando a realização de práticas de cuidados com a saúde. 
A escola ao proporcionar o programa de ginástica laboral traz aos professores uma alternativa viável de efetivação e um alerta de que a adoção de prática de exercícios regulares traz muitos benefícios à saúde.

Segundo Zankoski (2013) existem algumas condições que podem levar o aparecimento de diversas doenças, a falta de atividade física é um fator preponderante que acarreta muitos problemas de saúde e está no mesmo nível do surgimento de doenças associadas ao tabagismo, hipertensão, hipercolesterolemia. A atividade física está totalmente ligada à qualidade de vida, pois com sua realização é possível diminuir o stress, proporcionar sensação de prazer, liberdade, trazendo ainda mais bem estar físico e emocional o que deixará o profissional em condições ideais para o desenvolvimento de suas atividades laborais e atividades de socialização.

Com a melhoria no ambiente de trabalho gerado pela prática da ginástica laboral, a mesma ultrapassa o contexto doemprego, pois atua na promoção da saúde e estimula o profissional a praticar exercícios físicos, diminuindo os riscos à saúde, riscos de acidentes de trabalho e diminuição do absenteísmo docente, pois o trabalhador passa a ter mais disposição proporcionando ainda aumento da autoestima e de sua capacidade no ofício, gerando a quebra da rotina no serviço (BRITO; MARTINS, 2012).

\section{RESULTADOS E DISCUSSÃO}

O objetivo do presente estudo aspirava compartilhar o caminho percorrido pela ação na escola no intuito de se promover a conscientização sobre a importância da prática de atividade física regular aliviando as tensões e promovendo a qualidade de vida docente. Após a experiência com a Ginástica Laboral, de acordo com as condutas dos participantes, o escopo foi alcançado.

Pode-se inferir de acordo com os comentários dos professores a presença de uma consciência e preocupação na busca por hábitos de vida saudável, demonstrando motivação, satisfação no trabalho e envolvimento com os pares.

Eu achava que ginástica laboral tinha só em empresa, e eu por ter uma vida corrida, trabalhar em dois turnos, ter filhos, marido e casa para administrar e também não gostar de fazer exercícios me senti muito bem e comecei a sentir que no final do dia por mais que estivesse cansada, com a ginástica conseguia relaxar e até quanto minha postura corporal estou mais atenta. (Professor $A$ )

Até depois das atividades aqui na escola, comecei a sentir que a minha coluna que doía muito melhorou, foi então que comecei a praticar atividade física três vezes por semana. Para quem não fazia nada foi uma vitória e percebi que até minha produtividade com os alunos melhorou. (Professor B)

A ação interventiva corroborou com as pesquisas de Zankoski (2013) e Silva, Baia, Romanholo, Soares (2015), que tratam do sedentarismo vivenciado por muitos professores, além da questão sobre a importância da ginástica laboral em benefício da qualidade de vida docente. Infere-se que o comportamento dos professores, durante as atividades estão de acordo com as afirmações de Lima (2007) ao revelar que a ginástica laboral traz resultados positivos a quem realiza contribuindo e gerando motivação, diminuindo o stress e aumentando sua produção.

Com esta atividade me sinto mais envolvida com os colegas de trabalho, agora além de trocar experiências sobre a sala de aula conversamos sobre atividade física. (Professor C) 
Silva, Baia, Romanholo, Soares (2015) discorre que praticar exercícios físicos regularmente contribui para recuperação, prevenção e promoção de melhores condições de saúde, sendo a atividade física fator importante para que as estruturas corporais estejam sempre em condições de gerar bem-estar e qualidade de vida.

Sinto-me muito animada, com vontade de trabalhar, em pensar que houve épocas que eu precisei de licença da escola por problemas na coluna. (Professor D)

Observou-se ainda que os professores queixavam-se de dores osteomusculares, principalmente por não terem como hábito à prática regular de exercícios físicos e que a inserção da ginástica laboral proporcionou diminuição das dores. Os docentes ainda demonstraram o interesse na continuidade da prática de Ginástica Laboral na unidade de trabalho.

As atividades aguçaram minha curiosidade na busca por realizar exercícios físicos em casa, fico pesquisando vídeos no Youtube sobre exercícios e depois ainda compartilho com os colegas de trabalho. (Professor B)

Espero que no próximo ano o projeto continue, pois temos uma carga de trabalho tão puxada, e atividades físicas nos ajudam muito. (Professor $E$ )

Ressalta-se que a elaboração do material infográfico contribuiu para compartilhar uma maneira clara de se exercitar e favorecer a promoção da saúde.

\section{CONSIDERAÇÕES FINAIS}

Pôde-se verificar com a experiência relatada que os efeitos da Ginástica Laboral como intervenção provocaram mudanças de comportamentos nos participantes, gerando maior disposição e ânimo para o trabalho. Eles compreenderam que há diferentes possibilidades de realizar atividades físicas e o mais importante é encontrar àquela que possibilita satisfação durante a sua execução.

Com a adesão dos docentes, houve melhora no relacionamento com os pares e com os alunos, a ação de intervenção passou a fazer parte das metas do Projeto Político Pedagógico da escola que contará com o apoio do profissional de Educação Física para a realização da prática de Ginástica Laboral com os docentes duas vezes por semana na unidade escolar.

Dessa forma, a Ginástica Laboral pode ser considerada um recurso de combate frente ao problema do sedentarismo, pois é considerado um exercício físico eficaz na prevenção de doenças relacionadas ao trabalho, pode promover a saúde e melhorar a qualidade de vida do professor trazendo benefícios significativos para os indivíduos que praticam.

Sem a pretensão de esgotar as pesquisas relacionadas ao tema, a proposta da experiência apresentada, buscou contribuir para a compreensão sobre a importância da prática de atividade física regular aliviando as tensões e promovendo bem-estar ao docente.

De acordo com o presente estudo, ao constatar as dificuldades dos professores em realizar atividades físicas por falta de tempo, sugerem-se pesquisas relacionadas aos benefícios da prática regular de exercícios em casa com o auxílio de canais no Youtube que orientam e incentivam essa modalidade na própria residência, uma vez que o acesso a esse recurso midiático é simples. "As tecnologias digitais hoje são muitas, acessíveis, instantâneas e podem ser utilizadas para aprender em qualquer lugar, tempo e de múltiplas formas". (MORAN, 2018 p.9). Dessa maneira, a prática da Ginástica 
Laboral pode ocorrer sem a presença física do profissional da área de Educação Física desde que bem acompanhada por uma explicação detalhada no canal de grande circulação da internet.

É possível verificar que a tecnologia é uma aliada na promoção da saúde, visto que a vida cotidiana e os horários de trabalhos muitas vezes não possibilitam realização de atividade física em locais apropriados para esse fim e os recursos tecnológicos viabilizam a prática de exercícios com orientação profissional em qualquer momento do dia e local. Sua contribuição é de suma importância para a sociedade como um todo, principalmente, ao considerar o período que vivenciamos atualmente de distanciamento social devido à Pandemia da COVID-19.

\section{REFERÊNCIAS}

ANDRADE, Polyanna Peres; VEIGA, Heila Magali da Silva. Avaliação dos trabalhadores acerca de um programa de qualidade de vida no trabalho: validação de escala e análise qualitativa. Psicologia: Ciência e Profissão. Brasília, v.32, n.2, p. 304-319, 2012.

BAZANI, Sueli Erthal; GOES, Ana Paula; RIBAS, Cíntia Cargnin Cavalheiro. Ginástica laboral para professores e funcionários. 2010. Eixo: Prática em gestão escolar. Disponível em : http://http://www.opet.com.br/faculdade/revista-praxis/pdf/n4/gestao-ginastica-laboral-paraprofessores-e-funcionarios.pdf. Acesso em: 19 nov.2019.

BRASIL. Base Nacional Comum Curricular (BNCC). Brasília: MEC. 2018. Disponível em: http://basenacionalcomum.mec.gov.br/images/BNCC_20dez_site.pdfAcesso em: 19 nov.2019.

BRITO, Élyda Cristina de Oliveira; MARTINS, Caroline de Oliveira. Percepções dos participantes de programa de ginástica laboral sobre flexibilidade e fatores relacionados a um estilo de vida saudável. Revista Brasileira Promoção Saúde. Fortaleza, v.25, n.4, p. 445-454, out/dez., 2012.

DOMINIENSE, Franciele Nunes; MANN, Luana. Impactos de um programa de ginástica laboral em professores da APAE de Barreiras, BA. 2015. Revista Digital. Disponível em: http://www.efdeportes.com/efd214/programa-de-ginastica-laboral-em-professores.htm. Acesso em 19 nov. 2019

FERRÃO, Suzy Sayonara Ferreira. A Contribuição da ginástica laboral na manutenção da saúde dos professores da escola municipal Arnaldo Setti-GO. Planaltina: UnB, 2012. Trabalho de Conclusão de Curso (Licenciatura em Educação Física) - Universidade de Brasília, 2012.

LIMA, Deise Guadalupe de. Ginástica Laboral: metodologia de implantação de programar com abordagem ergonômica: Jundiaí, SP: Editora Fortuna, 2004.

LIMA, Valquíria de. Ginástica Laboral: atividade física no ambiente de trabalho. 3. ed.rev. e ampliada. São Paulo: Phorte, 2007.

MORAN, José Manuel. Contribuição das tecnologias para a transformação da educação. Revista Com Censo \# 14. v.5, n. 3, agosto, 2018. Disponível

em: http://www2.eca.usp.br/moran/wpcontent/uploads/2018/08/Entrevista_Tecnologias_Moran_Co m_Censo.pdf. Acesso em 19 nov. 2019.

MÓ, José Rogério Rodrigues; VIEIRA, Fernando de Oliveira; SANTOS, Vânia Martins dos. A

Ginástica Laboral como uma ferramenta de mudança de comportamento. VII Simpósio de Excelência em Gestão e Tecnologia - 2010. Disponível em: 
http://www.aedb.br/seget/arquivos/artigos10/299_GINASTICA\%20LABORAL\%20COMO\%20UMA\% 20FERRAMENTA\%20DE\%20MUDANCA\%20DE\%20COMPORTAMENTO.pdf. Acesso em 25jan. 2021.

SILVA, Luigi de Oliveira; BAIA, Fernando Costa; ROMANHOLO, Rafael Ayres; SOARES, Weliton Nunes. Nível de sedentarismo em professores do ensino regular da rede pública do Município de Cacoal - RO. Revista Brasileira de Prescrição e Fisiologia do Exercício, São Paulo. v.9. n.52. p166-174. mar/abr., 2015.

ZAMBAN, Danieli; COSTA, Gisele M. Tonin. A importância da ginástica laboral na prevenção de doenças ocupacionais. Revista de Educação do IDEAU, Rio Grande do Sul v.8. n.18. p 1-16. jul/dez., 2013

ZANKOSKI Sonia Maria. Ginástica laboral e a promoção da saúde docente In Os desafios da escola pública paranaense na perspectiva do professor PDE: Paraná: Produções didáticopedagógicas, 201. Disponível em:

http://www.diaadiaeducacao.pr.gov.br/portals/cadernospde/pdebusca/producoes_pde/2013/2013_ ufpr_edfis_artigo_sonia_maria_zankoski.pdf. Acesso em 19 nov. 2019.

Submissão: 29/08/2020

Aceito 02/02/2021 